\title{
Evaluation of Discordance in Differentiated Thyroid Cancer Patients with Negative Radioiodine Scans and Positive Thyroglobulin Values at the Ablation Outcome Control
}

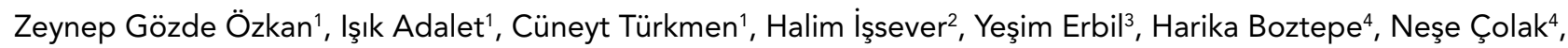 \\ Ferihan $\mathrm{Aral}^{4}$ \\ 'Department of Nuclear Medicine, istanbul Faculty of Medicine, İstanbul University, İstanbul, Turkey \\ ${ }^{2}$ Department of Public Health, İstanbul Faculty of Medicine, İstanbul University, Istanbul, Turkey \\ ${ }^{3}$ Department of General Surgery, İstanbul Faculty of Medicine, İstanbul University, İstanbul, Turkey \\ ${ }^{4}$ Department of Endocrinology and Metabolic Diseases, İstanbul Faculty of Medicine, İstanbul University, İstanbul, Turkey
}

\section{ABSTRACT}

Objective: We aimed to evaluate the discordance of $5 \mathrm{mCi}(185 \mathrm{MBq}) \mathrm{l}-131$ whole body scan (WBS) and thyroglobulin (Tg) values at the ablation outcome control in differentiated thyroid cancer (DTC) patients who had thyroidectomy and then received radioiodine (RAI) ablation.

Materials and Methods: We retrospectively evaluated 36 DTC patients who had RAl treatment in our department between $1992-2009$ and whose 5 $\mathrm{mCi}(185 \mathrm{MBq}$ ) I-131 WBS were negative, but Tg values were $\geq 2 \mathrm{ng} / \mathrm{ml}$ during the ablation outcome control (Patient group). Thirty-six patients whose Tg values were $<2 \mathrm{ng} / \mathrm{ml}$ and showed no discordance at the same control made up the control group. Patient and control groups were compared in terms of age, gender, histopathological features, ablation dose, Tg value before ablation, and 24. hour RAl uptake value during ablation. The patient group was then evaluated for the cause of the discordance.

Results: There were 28 female and 8 male patients whose mean age was $45.6 \pm 11.39$ in patient group. In the control group, there were 29 female and 7 male patients whose mean age was $41.5 \pm 11.69$. According to the reason of discordance at the ablation outcome control, the patient group was divided into 2 groups: 15 (42\%) patients (9 female, 6 male patients, mean age: 50.66 10.73 ) who had metastatic lymph nodes as the reason of discordance constituted the lymph node group. The remaining 21 (58\%) patients (19 female, 2 male patients, mean age: 41.5 \pm 10.44 ) were the micrometastatic group in which the cause of discordance could not be determined. There were statistically significant differences in soft tissue invasion ( $p<0.003)$, Tg levels before RAI treatment $(p<0.002)$, and diameter of tumor $>2 \mathrm{~cm}(p<0.035)$ between patient and control groups. Among the patient group, male gender $(p<0.03)$, diameter of tumor $>2 \mathrm{~cm}(p<0.05)$, thyroid capsule invasion $(p<0.03)$, and age $>40(p<0.01)$ were significantly different between lymph node and micrometastatic groups.

Conclusion: I-131 WBS/Tg level discordance at the ablation outcome control is mainly caused by metastatic lymph nodes.

Key Words: Differentiated thyroid carcinoma, radioiodine ablation, I-131 whole body scan, lymph node metastases

Received: $13.06 .2010 \quad$ Accepted: 07.03 .2011

\section{Introduction}

Differentiated thyroid cancers (DTC) constitute the majority of all thyroid cancers (1). Disease-free survival rate is more than $90 \%$ at 10 years, but there is still a group of patients who suffer from persistant or recurrent disease (2).

Total or near-total thyroidectomy is the first step of the treatment. Then high dose radioactive iodine-131 (I-131) (RAl) is given to the patient both to ablate the residual thyroidal tissue and destroy the metastases. In routine practice, a low dose (1-2 $\mathrm{mCi} ; 37-74 \mathrm{MBq})$ radioiodine scanning to assess the postoperative residual thyroid tissue and possible metastatic foci is not done before RAl ablation because even with low doses of radioiodine, stunning of the cells may occur, which diminishes the uptake of the RAl ablation dose. After RAl ablation, thyroid stimulating hormone (TSH) suppression treatment with L-thyroxine is given to the patient for the rest of his life to suppress the proliferative effect of TSH on thyroidal tissues or metastases.

Ablation outcome is assessed (ablation outcome control) 6-12 months after high dose RAl ablation. After the withdrawal of suppression treatment or administration of recombinant TSH, TSH is expected to rise to a minimum of $30 \mathrm{mlU} / \mathrm{L}$. Stimulation of TSH enables the augmentation of radioiodine uptake by the tissues. $1-5 \mathrm{mCi}(37-185 \mathrm{MBq})$ of radioiodine is given orally to the patient and after 48 hours, diagnostic I-131 whole body scan (I-WBS) is done. During this process, levels of thyroglobulin (Tg) and anti-Tg antibodies are also measured. 
$\mathrm{Tg}$ is a thyroid-specific protein with a diameter of $660 \mathrm{kDa}$ which is the precursor element of thyroid hormone biosynthesis (3). It is secreted from either normal thyroid tissue or functioning metastases of thyroid cancer. It is predicted that after total/near-total thyroidectomy and RAl ablation, Tg levels would be near zero. During the follow-ups, any increased level of Tg suggests that there is a thyroid tissue which could not be ablated or there are metastases. In the presence of anti-Tg antibodies, levels of Tg can be mistakenly low.

Normally, there is a concordance between I-WBS and Tg levels. A negative I-WBS and Tg level $<2 \mathrm{ng} / \mathrm{ml}$ suggests that the thyroid tissue is totally ablated. On the other hand, a positive I-WBS and $\mathrm{Tg} \geq 2 \mathrm{ng} / \mathrm{ml}$ point to residual disease and make the clinician continue with further treatments. Whether to continue with further treatments or simply monitoring the patient closely at short time intervals is still debated because aggressive treatment of minimal residual disease has not been proven to increase patient survival rates yet (4).

There are many investigations which revealed positive $\mathrm{Tg}$ level and negative I-WBS discordance seen during follow-ups of patients, but there are only few articles about this discordance detected at the ablation outcome control process. Therefore, in this study, we compared features of patients whose I-WBS and Tg levels are negative in the ablation outcome control with those of the patients with negative I-WBS, but positive Tg levels. We investigated the cause of this discordance and the outcomes of further treatments.

\section{Material and Methods}

\section{Material}

Thirty-six patients who had total or near total thyroidectomy and RAl ablation because of differentiated thyroid cancer between 1992-2009 and whose I-WBS were negative and Tg levels $\geq 2 \mathrm{ng} / \mathrm{ml}$ during the ablation outcome control were taken as the patient group. For the control group, 36 patients whose I-WBS were negative and $\mathrm{Tg}<2 \mathrm{ng} / \mathrm{ml}$ at the ablation outcome control were selected randomly.

After TSH stimulation, $5 \mathrm{mCi}$ (185 MBq) l-131 was given orally to the patients and 2 days later, I-WBS were carried out. The mean value for TSH was $108.8 \mathrm{mlU} / \mathrm{L}$ in the patient group and $93.7 \mathrm{mIU} / \mathrm{L}$ in the control group. All Tg and anti-Tg antibody levels were obtained by electrochemiluminescence method, simultaneously with TSH. During I-WBS scans, we took whole body anterior-posterior images. Also in every patient, static images of the neck were taken. We could not perform SPECT or SPECT-CT imaging during radioiodine scanning.

In our study, ablation outcomes were assessed at 6-15 months (mean: 10 months) after RAl ablation.

The patients with high levels of anti-Tg antibodies or distant metastases were not selected for either patient or control groups. Therefore, none of the patients in our study group had high levels of anti-Tg antibodies or distant metastases throughout their course of follow-ups.

Low dose whole body radioiodine scanning before RAl ablation had not been done to any of the patients in order to prevent stunning of the cells.

\section{Methods}

For the determination of factors which led to the discordance at the ablation outcome control age, gender, histopathological features (such as diameter of tumor, subgroups, multifocality, bilaterality, lymphatic invasion, vascular invasion, tumor capsule invasion, thyroid capsule invasion, soft tissue invasion, intrathyroidal proliferation, rest tumor on surgical margin), dose of ablation therapy, Tg measurements before ablation treatment, and RAl uptake values during ablation were investigated statistically by using Ki-square, Mann-Whitney $U$, and multivariate logistic regression analysis tests between patient and control groups.

In the patient group, the data which was gathered from the radiological or scintigraphical studies that had been carried out to find out the reason for discordance was then evaluated. In most of the patients, neck ultrasound (USG) was chosen. Computed tomography (CT) of thorax, magnetic resonance (MR) of neck, and F18-fluorodeoxyglucose (FDG) positron emission tomography (PET)-CT were chosen in fewer patients. According to this data, the patient group was then divided into 2 groups, according to the cause of the discordance.

\section{Results}

In the patient group, there were 28 female and 8 male patients whose mean age was $45.6 \pm 11.39$. In the control group, there were 29 female and 7 male patients, and the mean age was $41.5 \pm 11.69$.

The histopathologic information on the patients of both groups are given on Table 1. In the patient group, the information about size of tumor, multifocality, bilaterality, lymphatic invasion, vascular invasion, tumor capsule invasion, thyroid capsule invasion, soft tissue invasion, intrathyroidal proliferation, and rest tumor on the surgical margin could not be found in 2 patients. In 1 of those patients, the histopathologic subgroup was also unknown, although the patient was referred to our department as a differentiated thyroid cancer patient.

The other features of the patients which were evaluated during statistical analysis are given in Table 2. For any invasions of tumor or poor prognostic features, such as subtypes of diffuse sclerosing, tall or columnar cell, age $>40$ years old or diameter of tumor $>2 \mathrm{~cm}$, the ablation dose was chosen to be $150 \mathrm{mCi}(5550 \mathrm{MBq})$ instead of $100 \mathrm{mCi}(3700 \mathrm{MBq})$. RAl uptakes were measured at the $24^{\text {th }}$ hour.

Six patients in the patient group and 10 patients in the control group had cervical lymph node dissections during their thyroidectomy operations. All of the dissected lymph nodes were metastatic.

According to analysis between patient and control groups, there were statistically significant differences in soft tissue invasion $(p<0.003)$ and $\mathrm{Tg}$ values before ablation $(p<0.002)$. When patient and control groups were taken as dependent variables in multivariate logistic regression analysis, soft tissue invasion ( $p<0.004$, odds ratio (OR): $12,95 \%$ confidence interval (Cl): 2.19-66.77), Tg value before ablation ( $p<0.001$, OR: 1.07, 95\% Cl: 1.02-1.12), and tumor diameter $>2 \mathrm{~cm}(\mathrm{p}<0.035$, OR: $5.45,95 \% \mathrm{Cl}: 1.12-26.47)$ were found to cause discordance. 
Table 1. Histopathologic features of the patients

\begin{tabular}{|c|c|c|}
\hline & Patient Group & Control Group \\
\hline \multirow[t]{2}{*}{ Diameter of tumor } & $>2 \mathrm{cm:} 12$ & $>2 \mathrm{~cm}: 6$ \\
\hline & $\leq 2 \mathrm{cm:} 22$ & $\leq 2 \mathrm{~cm}: 30$ \\
\hline Histopathologic subgroup & $\begin{array}{c}\text { Classical type papillary: } 16 \\
\text { Nonclassical type papillary: } 15 \\
\text { Follicular: } 3 \\
\text { Other: } 1\end{array}$ & $\begin{array}{c}\text { Classical type papillary: } 15 \\
\text { Nonclassical type papillary: } 19 \\
\text { Follicular: } 0 \\
\text { Other: } 2\end{array}$ \\
\hline Multifocality & $\begin{array}{l}(+): 5 \\
(-): 29\end{array}$ & $\begin{array}{l}(+): 14 \\
(-): 22\end{array}$ \\
\hline Bilaterality & $\begin{array}{l}(+): 6 \\
(-): 28\end{array}$ & $\begin{array}{l}(+): 9 \\
(-): 27\end{array}$ \\
\hline Tumor capsule invasion & $\begin{array}{l}(+): 12 \\
(-): 22\end{array}$ & $\begin{array}{l}(+): 16 \\
(-): 20\end{array}$ \\
\hline Thyroid capsule invasion & $\begin{array}{c}(+): 25 \\
(-): 9\end{array}$ & $\begin{array}{l}(+): 16 \\
(-): 20\end{array}$ \\
\hline Vascular invasion & $\begin{array}{l}(+): 11 \\
(-): 23\end{array}$ & $\begin{array}{l}(+): 5 \\
(-): 31\end{array}$ \\
\hline Lymphatic invasion & $\begin{array}{l}(+): 11 \\
(-): 23\end{array}$ & $\begin{array}{l}(+): 10 \\
(-): 26\end{array}$ \\
\hline Soft tissue invasion & $\begin{array}{l}(+): 18 \\
(-): 16\end{array}$ & $\begin{array}{l}(+): 7 \\
(-): 29\end{array}$ \\
\hline Rest tumor on surgical margin & $\begin{array}{l}(+): 4 \\
(-): 30\end{array}$ & $\begin{array}{l}(+): 4 \\
(-): 32\end{array}$ \\
\hline Intrathyroidal proliferation & $\begin{array}{c}(+): 13 \\
(-): 21\end{array}$ & $\begin{array}{c}(+): 12 \\
(-): 24\end{array}$ \\
\hline
\end{tabular}

After the ablation outcome control process, the causes of I-WBS and Tg level discordance were evaluated in the patient group. According to these data, the patient group was divided into 2 groups according to the cause of the discordance. The first group which was called the lymph node group, consisted of 15 patients (42\%) with lymph node metastases as the cause of the discordance ( 9 female, 6 male patients, mean age: $50.66 \pm 10.73$ ). The lymph nodes were $5.9-50 \mathrm{~mm}$ in diameter, measured either with USG or CT and were located mainly on the neck, only a few in the mediastinum. The mean value of the diameters was $15.1 \mathrm{~mm}$ and the median value was $11 \mathrm{~mm}$.

In the second group, there were 21 patients (58\%): (19 female, 2 male patients, mean age: $41.5 \pm 10.44)$. In this group, no particular cause could be found. The reasons such as improper patient preparation or loss of iodine trapping were excluded either by questioning the patients or by PET-CT scans in selected patients. Therefore, for this group, we assumed that the sizes of the metastases were too small to be able to be detected and therefore named the group as the micrometastatic group.

Between the lymph node and micrometastatic groups, there were statistically significant differences in male gender $(p<0.03)$, tumor diameter $>2 \mathrm{~cm}(p<0.05)$, thyroid capsule invasion of the tumor $(p<0.03)$, and age $>40$ years $(p<0.01)$. When these groups were taken as dependent variables in multivariate logistic regression analysis, only tumor diameter $>2$ $\mathrm{cm}(\mathrm{p}<0.01$, OR: $34.35,95 \% \mathrm{Cl}: 1.79-655.76)$ and age $>40$ years ( $p<0.008$, OR: $1.22,95 \% \mathrm{Cl}: 1.05-1.42)$ remained significant.

Tumor diameter $>2 \mathrm{~cm}$ increased the likelihood of both discordance in ablation outcome control process and also the presence of lymph node metastases. Soft tissue invasion of the tumor increased the likelihood of discordance. Tg level $\geq 10 \mathrm{ng} / \mathrm{ml}$ before ablation increased the likelihood of discordance, whereas age $>40$ increased the possibility of lymph node metastases.

Follow-up range was 2-13 years (median: 3 years) in the lymph node group and 2-24 years (median: 4 years) in the micrometastatic group. The treatments which were given after the detection of discordance to the patients are listed in Table 3.

In the lymph node group, 11 patients received RAl treatment after the detection of the cause of discordance. There were radioiodine uptakes on the therapeutical whole body scans (tWBS) which were done 10 days after RAl treatments in 9 patients (Figure 1). In one of the patients who had surgery, a second primary tumor was detected.

In the micrometastatic group, 11 patients received RAI treatments. In 6 patients, there were radiodine uptakes on tWBS (Figure 2).

In summary, 24 of 36 patients received treatment. Six of those were accepted as being in remission during the followups, whereas in 7 patients, the treatment response had not been controlled. In 11 patients, Tg levels were still high. 
Table 2. Clinical features of the patients

\begin{tabular}{|lcc|}
\hline & Patient Group & Control Group \\
\hline Ablation doses * & $100 \mathrm{mCi}(3700 \mathrm{MBq}): 13$ & $100 \mathrm{mCi}(3700 \mathrm{MBq}): 14$ \\
& $150 \mathrm{mCi}(5550 \mathrm{MBq}): 23$ & $150 \mathrm{mCi}(5550 \mathrm{MBq}): 22$ \\
Tg levels before ablation & $<10 \mathrm{ng} / \mathrm{ml}: 4$ & $<10 \mathrm{ng} / \mathrm{ml}: 23$ \\
& $\geq 10 \mathrm{ng} / \mathrm{ml}: 23$ & $\geq 10 \mathrm{ng} / \mathrm{ml}: 10$ \\
RAl uptakes during ablation ** & Unknown: & Unknown: 3 \\
& $<5 \%: 9$ & $<5 \%: 14$ \\
& $\geq 5 \%: 11$ & $\geq 5 \%: 17$ \\
\hline *l-131 doses given during ablation; ${ }^{* * 24 . ~ h o u r ~ I-131 ~ u p t a k e ~ v a l u e s ~ d u r i n g ~ a b l a t i o n ~}$ & Unknown: 5 \\
\hline
\end{tabular}

Table 3. Treatments given to the patients after the detection of discordance.

\begin{tabular}{|lcc|}
\hline & $\begin{array}{c}\text { Lymph node group } \\
(\mathrm{n}: 15)\end{array}$ & $\begin{array}{c}\text { Micrometastatic group } \\
(\mathrm{n}: 21)\end{array}$ \\
\hline Surgery & 2 & - \\
RAI & 6 & 11 \\
Surgery+RAl & 5 & - \\
No treatment & 2 & 9 \\
Unknown & - & 1 \\
\hline
\end{tabular}

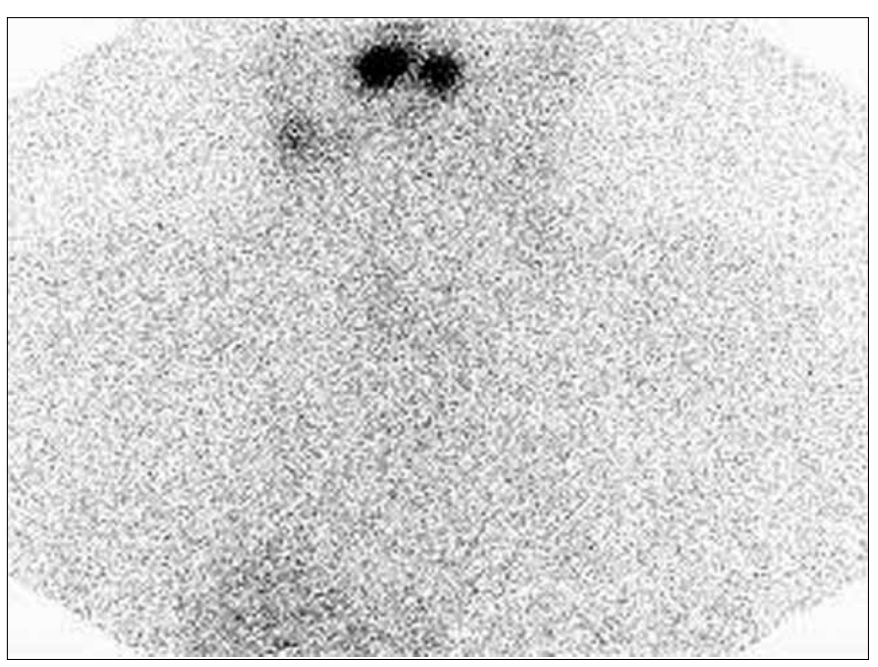

Figure 1. Forty-one year old, male patient. Although I-WBS was negative, Tg level was high during ablation outcome control. Then he had an USG which revealed a lymph node in the right submandibular region. Although fine needle aspiration biopsy was benign, the patient was given $150 \mathrm{mCi}(5550 \mathrm{MBq})$. During RAl treatment his laboratory values were TSH: $93 \mathrm{mIU} / \mathrm{L}, \mathrm{Tg}: 42.6 \mathrm{ng} / \mathrm{ml}$, anti-Tg: $44 \mathrm{lU} / \mathrm{ml}$ (normal range: 0-115 IU/ml). An uptake is seen in the submandibular region which belongs to the lymph node

Eleven of 36 patients had not been given treatment. After the follow-ups, 9 of those patients were accepted as either in remission or having a stable disease. In 2 patients, Tg levels began to rise during controls. One of 36 patients was lost to follow-up.

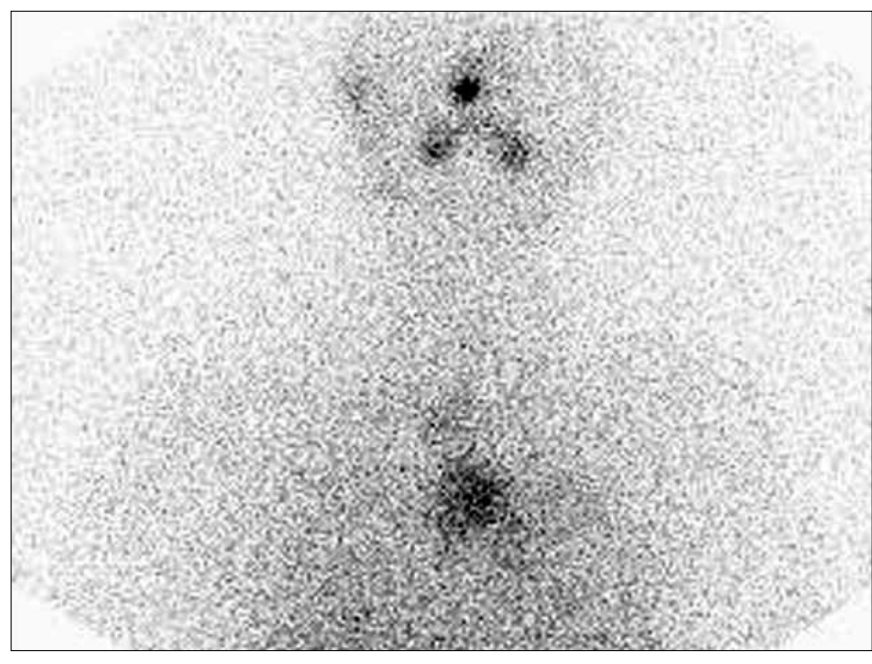

Figure 2. Twenty-six year old, female patient. I-WBS was negative, but $\mathrm{Tg}$ was high in her ablation outcome control. There was neither a residual thyroid tissue, nor a metastatic focus on the following diagnostics studies. She was given $150 \mathrm{mCi}$ (5550 MBq) RAl treatment when TSH: $64.64 \mathrm{mlU} / \mathrm{L}$, Tg: $13.7 \mathrm{ng} / \mathrm{ml}$, anti-Tg: $12.26 \mathrm{IU} / \mathrm{ml}$ (normal range: 0-115 $\mathrm{IU} / \mathrm{ml}$ ). An uptake is seen in the mediastinum. In the MR taken after tWBS, there was no remnant of thymic tissue

During follow-ups, no patient had any serious morbidity or mortality.

\section{Discussion}

The patients who have DTC have quite a long life span when compared with the patients who have other types of malignancies. The overall 1-, 2-, 5-, and 10-year survival rates are said to be $98.2 \%, 97.4 \%, 96.5 \%$, and $96.5 \%$ respectively (5). On the other hand, the recurrence is common (15-30\% of patients), even in early-stage disease (6). Early diagnosis enables early treatment of residual disease when the treatment will probably be more effective (4).

One of the problems frequently seen during the followups of DTC patients is Tg level and I-WBS discordance at the ablation outcome control, which is a sign of residual or metastatic disease. In our study, lymph node metastases were responsible of this discordance in $42 \%$ of the cases. Also in our study, soft tissue invasion of the tumor, tumor diameter $>2 \mathrm{~cm}$, 
and $\mathrm{Tg}$ level $\geq 10 \mathrm{ng} / \mathrm{ml}$ before receiving RAl ablation were found to cause discordance. Similarly, Alzahrani et al found that perithyroidal tumor extension, soft tissue invasion, cervical lymph node metastases and high Tg level before RAl ablation were associated with discordance (7).

All histological variants of thyroid tumors are seen more frequently in females. Papillary carcinoma has been found in $80 \%$ of female cases. Thyroid tumors usually occur in the third, fourth, and fifth decades of life (8). As age increases, the female/male ratio declines from 5 at ages $20-24$ to 3.4 at ages 35-44 and approaches 1 at ages $80+$ (9). In our study, we found that in males and age $>40$, lymph node involvement which led to metastatic disease was common. Zaydfudim et al revealed that lymph node involvement was associated with $46 \%$ increased risk of death (10). Wada et al. (11) found that younger patients ( $\geq 45$ years old), even when they presented with palpable lymphadenopathy, had a favorable prognosis.

The rate of neck lymph node metastases varies from $5-20 \%$ (12) up to $70 \%$ (2) in papillary thyroid cancers. In our study, male gender, tumor diameter $>2 \mathrm{~cm}$, thyroid capsule invasion, and age $>40$ were significantly associated with lymph node involvement. Very similarly, Ito et al found that male gender, age 55 years or over, maximal tumor diameter larger than 3 $\mathrm{cm}$, and massive extrathyroid extension were associated with lymph node involvement and they recommended prophylactic modified radical neck dissection (13). Bardet et al. (12) emphasized that, because almost half of lymph node metastases occurred in the year following the diagnosis, it was probable that most patients with lymph node metastases have persistent or residual disease rather than a recurrence. Similarly, in our patient group, 11 patients had lymphatic invasion of the tumor and 6 patients had lymph node metastases during the diagnosis, and in 15 patients lymph node metastases were determined during the ablation outcome control process. High rate of lymph node detection during ablation outcome control could have also been the result of the limited neck dissection which is preferred in our hospital for the primary operation. During total thyroidectomy operations, palpable, preoperatively detected lymph nodes, which are also explored during the operation, are resected. The micrometastatic small lymph nodes which are not resected, grow in size after a period of time. Limited neck dissection is associated with cervical recurrence (14). Low et al. (3) found a significant inverse relationship between total number of lymph nodes resected and $\mathrm{Tg}$ level at 12 months after the surgery.

When preoperative USG shows no malignant lymph nodes or shows only in the central compartment, dissection of the central compartment is sufficient, but if the primary tumor is large $(\geq 4 \mathrm{~cm})$ and/or there is distant metastasis, then there is high risk of recurrence in the lateral cervical compartment (15). Also, during reoperation, there is a risk of complications. In one study, out of 22 neck reoperations, 2 patients developed permanent hypoparathyroidism and 4 patients have permanent recurrent laryngeal nerve paralysis (16). Gonzalez et al. (17) showed the effectiveness of preoperative USG in detecting nonpalpable metastatic lymph nodes and recommended preoperative neck USG to optimize primary surgical planning. Therefore, evaluating the patient before the operation and performing the appropriate neck dissection are essential. Both in the preoperative state and also for the discordant cases during the ablation outcome control as in our study, USG has a major role. Especially the patients who have discordance of Tg levels and I-WBS at the ablation outcome control should have an USG, performed by an experienced radiologist because the normal anatomy of the neck is greatly changed after neck surgeries. Small sizes of the lymph nodes and postinflammatory lymph node hyperplasia are other reasons for insufficient or incorrect evaluation. (18). In the patients with high levels of Tg and negative I-WBS, the detection of lymph nodes increases the chance for surgery. In our study, median size of the lymph nodes in the lymph node group was $11 \mathrm{~mm}$ which can be a reason for the negative I-WBS. Because metastatic lymph nodes can be seen in $42 \%$ of the cases, in the patients with high levels of $\mathrm{Tg}$ and negative I-WBS, USG done by an experienced radiologist must be the first imaging modality to choose. Dedifferentiation of the tumor, iodine contamination, and low dose of iodine are the other possible reasons for the Tg positive/ I-WBS negative situation. For our patient group, the main reason seems to be the small sizes of the lymph nodes. For this reason, SPECT/CT may provide valuable information. Also focal radioiodine uptake in the organs like salivary glands, which concentrate iodine physiologically, makes detection of malignant deposits like lymph nodes harder (19). Again, SPECT/CT may provide valuable information. In their investigation, Spanu et al. (20) showed that SPECT/CT had an incremental value over planar images in $67.8 \%$ of patients, modified therapy in $35.6 \%$ of metastatic cases, and avoided unnecessary treatment in $20.3 \%$ of patients because SPECT/ CT identified additional 28 occult foci to planar images in 10 of 52 patients, 14 occult foci in 7 patients with negative planar images, and characterized 48 foci unclear on planar images in terms of location and extent. In the investigation of Schmidt et al. (18), SPECT/CT yielded a gain in information on nodal staging in $35 \%$ and altered risk stratification in $25 \%$ when compared with planar imaging. SPECT/CT has also a high negative predictive value in detecting occurence of cervical metastatic lymph nodes at the ablation outcome control (19).

Dedifferention is another reason for discordance. In 10 $15 \%$ of DTC patients, high levels of $\mathrm{Tg}$ are detected when radioiodine scans are negative (21). As a result of dedifferentiation, tumors may lose their ability to trap radioidiodine. In these patients, instead of using radioidione for whole body scanning, F18-FDG can be used for whole body imaging in PET-CT. Being a glucose analogue, F18-FDG is taken into the cells by GLUT-1 transporters. In dedifferentiated tumors, there are increased numbers of GLUT-1, which enable the high uptake of F18-FDG $(21,22)$. With its better resolution characteristics, in patients with elevated $\mathrm{Tg}$, but negative radioiodine scans, F18-FDG PET has a sensitivity of $69.3-94.6 \%$, specificity of $25-83 \%$, and accuracy of $63.9-87.8 \%$ in detecting recurrent/ metastatic disease (23).

In our study, only 6 of the patients who had received treatment after the detection of discordance were in remission or accepted as having a stable disease. Eleven of the patients that received treatment still had high levels of $\mathrm{Tg}$ and were accepted as having persistent disease. On the other hand, in 
9 patients who did not receive treatment, Tg levels decreased. In 2 patients who did not have any treatment, Tg levels increased during the follow-ups. Alzahrani et al. reported similar outcomes: Of 53 patients, 42 cases were followed without any therapeutic intervention. Thirty-one cases had spontaneous remission and 11 cases continued to have high Tg levels. Of the other 11 patients who had a therapeutic intervention (RAI, surgery, or external radiotherapy), 4 cases achieved remission, 5 cases continued to have persistent disease, and 2 cases had progression (7). Schmidt et al. (19) emphasized the efficacy of radioiodine treatment in metastatic lymph nodes. In their investigation, 18 of 22 radioiodine positive lymph nodes detected at the ablation were not detected at the ablation outcome control on the average of 5 months. They also mentioned that lymph nodes smaller than $0.9 \mathrm{ml}$ were eliminated by radioiodine $94 \%$, whereas for the larger nodes, this rate was 1 out of 4 . For this reason, they stated that it was rational to use a threshold in this range for the choice of radioiodine therapy or resurgery.

\section{Conclusion}

If there is a discordance of negative WBS and positive Tg values at the ablation outcome control, the first thing which must be done is to search for metastatic lymph nodes. After the determination of the cause of discordance with diagnostic studies, the choice of treatment (radioiodine therapy or resurgery) can be evaluated.

\section{Conflict of Interest}

No conflict of interest was declared by the authors.

\section{References}

1. Silberstein EB. The treatment of thyroid malignant neoplasm. In: Henkin RE, Bova D, Dillehay GL, Halama JR, Karesh SM, Wagner $\mathrm{RH}$, Zimmer Am (ed). Nuclear Medicine. Mosby Elsevier. Pennsylvania, USA, 2nd ed., 2006; pp 1576-87.

2. Leboulleux S, Rubino C, Baudin E, Caillou B, Hartl DM, Bidart $J M$, et al. Prognostic factors for persistent or recurrent disease of papillary thyroid carcinoma with neck lymph node metastases and/or tumor extension beyond the thyroid capsule at initial diagnosis. J Clin Endocrinol Metab 2005;90:5723-9. [CrossRef]

3. Low $H$, Delbridge L, Sidhu S, Learoyd D, Robinson B, Roach $P$, et al. Lymph node status influences follow-up thyroglobulin levels in papillary thyroid cancer. Ann Surg Oncol 2008;15:2827-32. [CrossRef]

4. Cooper DS, Doherty GM, Haugen BR, Kloos RT, Lee SL, Mandel SJ, et al. Revised American Thyroid Association management guidelines for patients with thyroid nodules and differentiated thyroid cancer. Thyroid 2009;19:1167-214. [CrossRef]

5. Lin YK, Sheng JM, Zhao WH, Wang WB, Yu XF, Teng LS, et al. Multifocal papillary thyroid carcinoma: clinical analysis of 168 cases. Zhonghua Wai Ke Za Zhi 2009;47:450-3.

6. Johnson NA, Tublin ME. Postoperative surveillance of differentiated thyroid carcinoma: rationale, technique, and controversies. Radiology 2008;249:429-44. [CrossRef]

7. Alzahrani AS, Mohamed G, Al Shammary A, Aldasouqi S, AbdalSalam S, Shoukri M. Long-term course and predictive factors of elevated serum thyroglobulin and negative diagnostic radioiodine whole body scan in differentiated thyroid cancer. J Endocrinol Invest 2005;28:540-6.

8. Manxhuka-Kerliu S, Devolli-Disha E, Gerxhaliu A, Ahmetaj H, Baruti $A$, Loxha $S$, et al. Prognostic values of thyroid tumours. Bosn J Basic Med Sci 2009:9:111-9.

9. Kilfoy BA, Devesa SS, Ward MH, Zhang Y, Rosenberg PS, Holford $T R$, et al. Gender is an age-spesific effect modifier for papillary cancers of the thyroid gland. Cancer Epidemiol Biomarkers Prev 2009;18:1092-100. [CrossRef]

10. Zaydfudim V, Feurer ID, Griffin MR, Phay JE. The impact of lymph node involvement on survival in patients with papillary and follicular thyroid carcinoma. Surgery 2008;144:1070-7. [CrossRef]

11. Wada N, Masudo K, Nakayama H, Suganuma K, Matsuzu K, Hirakawa $\mathrm{S}$, et al. Clinical outcomes of older or younger patients with papillary thyroid carcinoma: impact of lymphadenopathy and patient age. Eur J Surg Oncol 2008;34:202-7. [CrossRef]

12. Bardet S, Malville E, Rame JP, Babin E, Samama G, De Raucourt $D$, et al. Macroscopic lymph-node involvement and neck dissection predict lymph-node recurrence in papillary thyroid carcinoma. Eur J Endocrinol 2008;158:551-60. [CrossRef]

13. Ito $Y$, Higashiyama T, Takamura Y, Miya A, Kobayashi K, Matsuzuka $F$, et al. Risk factors for recurrence to the lymph node in papillary thyroid carcinoma patients without preoperative detectable lateral node metastasis: validity of prophlactic modified radical neck dissection. World J Surg 2007;31:2085-91. [CrossRef]

14. Davidson HC, Park BJ, Johnson JT. Papillary thyroid cancer: controversies in the management of neck metastases. Laryngoscope 2008;118:2161-5. [CrossRef]

15. Sugitani I, Fujimoto Y, Yamada K, Yamamoto N. Prospective outcomes of selective lymph node dissection for papillary thyroid carcinoma based on preoperative ultrasonography. World J Surg 2008;32:2494-502. [CrossRef]

16. Mirghani H, Francois A, Landry G, Hans S, Menard M, Brasnu D. Repeat of lymphatic dissection for thyroid cancers. Ann Otolaryngol Chir Cervicofac 2009;126:37-42. [CrossRef]

17. Gonzalez HE, Cruz F, O'Brien A, Goni I, Leon A, Claure R, et al. Impact of preoperative ultrasonographic staging of the neck in papillary thyroid carcinoma. Arch Otolaryngol Head Neck Surg 2007;133:1258-62. [CrossRef]

18. Schmidt D, Szikszai A, Linke R, Bautz W, Kuwert T. Impact of 131। SPECT/Spiral CT on nodal staging of differentiated thyroid carcino$\mathrm{ma}$ at the first radioablation. J Nucl Med 2009;50:18-23. [CrossRef]

19. Schmidt $D$, Linke $R$, Uder $M$, Kuwert T. Five months' follow-up of patients with and without iodine-positive lymph node metastases of thyroid carcinoma as disclosed by I131-SPECT/CT at the first radioablation. Eur J Nucl Med Mol Imaging 2010;37:699-705. [CrossRef]

20. Spanu A, Solinas ME, Chessa F, Sanna D, Nuvoli S, Madeddu G. I131 SPECT/CT in the follow-up of differentiated thyroid carcinoma: incremental value versus planar imaging. J Nucl Med 2009;50:184-90. [CrossRef]

21. Shammas A, Degirmenci $B$, Mountz JM, McCook BM, Branstetter B, Bencherif BB, et al. 18F-FDG PET/CT in patients with suspected recurrent or metastatic well-differentiated throid cancer. J Nucl Med 2007;48:221-6.

22. Schlüter B, Bohuslavizki KH, Beyer W, Plotkin M,Buchert R, Clausen M. Impact of FDG PET on patients with differentiated thyroid cancer who present with elevated thyroglobulin and negative I-131 scan. J Nucl Med 2001;42:71-6.

23. Hussain HK, Britton KE, Grossman AB, Reznek RH. Thyroid cancer. In: Husband JE, Reznek RH (ed). Imaging in Oncology. Taylor and Francis. London, UK, 2nd ed., 2004; pp 669-709. 